\title{
SPECIFICITY OF THE NATURE OF THE IMAGE IN THE SOCIO-CULTURAL SPACE
}

\author{
Sofya R. Kurokhtina \\ Saratov State University named by N.G. Chernyshevsky, Saratov, Russian Federation
}

\begin{abstract}
Among the researchers of the visual, visualization is singled out as one of the universal characteristics of modern culture. This trend is due to the growth of visual artefacts that are rapidly filling the socio-cultural space. Many factors contributed to this, and one of the main ones is the development of media communications. The discourse on visuality went beyond the boundaries of Art Studies, which entailed the study of non-artistic visuality - the everyday life of visible things. As a result of visual experience expansion, the processes of production and consumption of visual images have changed, which is reflected in social practices. Terminological difficulties encountered in the field of visual studies speak to the problems of visual studies institutionalization. Nevertheless, we can distinguish two polar theoretical approaches: according to the first approach, the image is understood as a "cultural" representation mediated by various ideological practices. This approach has been influenced by constructivism, which is reflected in the interest in analyzing the role of images in the formation of social and cultural meanings. Also, the representational theory of imagery deals with issues related to the view of the observer and its conditioning by various scopic regimes. This paradigm is considered to be subject to emancipation trends. It asserts the change of the concept of a passive spectator, captured by images, to the concept of a spectator, who actively participates in the creation of visual images. The second approach, which is considered in the article, interprets the image from the phenomenology point of view. The phenomenological approach to visual imagery focuses on the image-presentation concept, which exists autonomously from the observer, in the mode of semantic closure, which means that the visual image has its own content that is difficult for the subject to access. The presented concept excludes reading the image only as a reflection or representation of the socio-cultural field. It is concluded that the image theory is undergoing significant changes, and vision and the viewer are becoming more independent.

Key words: visuality, image, visual research, observer, view.
\end{abstract}

УДК 304.2

ББК 87.5

\section{СПЕЦИФИКА ПРИРОДЫ ОБРАЗА В СОЦИОКУЛЬТУРНОМ ПРОСТРАНСТВЕ}

\author{
Софья Руслановна Курохтина \\ Саратовский государственный университет им. Н.Г. Чернышевского, г. Саратов, Российская Федерация
}

\begin{abstract}
Аннотация. В среде исследователей визуального принято выделять визуализацию в качестве одной из универсальных характеристик современной культуры. Данная тенденция обусловлена ростом визуальных артефактов, стремительно наполняющих социокультурное пространство. Этому способствовало множество факторов, и одним из главных является развитие медиакоммуникаций. Дискурс о визуальности вышел из границ искусствознания, что повлекло за собой изучение нехудожественной визуальности - повседневной жизни видимых вещей. Вследствие расширения визуального опыта изменились процессы производства и потребления визуальных образов, что отразилось на социальных практиках. Терминологические трудности, встречающиеся в сфере исследований визуального, говорят о проблемах институционализации visual studies. Тем не менее, можно условно выделить два полярных теоретических подхода: согласно первому подходу, образ понимается в качестве «культурной» репрезентации, опосредованной различными практиками идеологического толка. Данный подход претерпел влияние конструктивизма, что выражается в интересе к аналитике роли образов в формировании социальных и культурных смыслов. Также репрезенталистская
\end{abstract}


теория образности рассматривает проблемы, касающиеся взгляда наблюдателя и его обусловленности различными скопическими режимами. Данная парадигма рассматривается как подлежащая тенденциям эмансипации. Она утверждает смену концепта пассивного зрителя, захваченного образами, на концепт зрителя, который активно участвует в создании визуальных образов. Второй подход, который рассматривается в статье, трактует образ с точки зрения феноменологии. Феноменологический подход к визуальной образности акцентирует внимание на понятии образа-презентации, который существует автономно от наблюдателя, в режиме смысловой закрытости. Это означает, что визуальный образ имеет собственное труднодоступное субъекту содержание. Представленная концепция исключает прочтение образа только в качестве отражения или репрезентации социокультурного поля. Делается вывод о том, что теория образа претерпевает существенные изменения, а зрение и зритель становятся все более самостоятельными.

Ключевые слова: визуальность, образ, визуальные исследования, наблюдатель, взгляд.

Визуальные исследования, возникшие как междисциплинарное направление на стыке искусствознания, социальной теории, философии, теорий медиа, объединили традиционные визуальные объекты с новыми формами визуальных проявлений, тем самым предоставив интеллектуалам почву для анализа. Среди визуальных теоретиков упрочилась тенденция к смешению традиционных живописных традиций, кино, фотографии со сравнительно новыми объектами, активно фигурирующими в социальном поле - медиа, рекламой, дизайном, модой и т. д. Постепенное стирание границ, которые ранее существовали между художественными и нехудожественными визуальными объектами, привело к тому, что визуальный опыт расширился, и, как следствие, изменились процессы потребления и производства визуальных образов. Сменился фокус рассмотрения визуального: ранее существование визуальных артефактов мыслилось в рамках специализированных мест - музеев, где потребление визуальности велось в ограниченном пространстве. Однако современные реалии таковы, что визуальные образы начали выходить из ограниченного пространства музея и стали восприниматься как часть повседневного мира. Данная тенденция обусловлена тем, что происходит стремительное наполнение социокультурного пространства медиа-визуальностью. Поэтому вопрос о самостоятельности визуальных образов в жизненном мире человека, их подчеркнутая активность являются превалирующими над вопросами о феномене и формах визуального.

Парадигмальные основания визуальных исследований обычно принято связывать с лингвистическим поворотом, который отказывает в доминировании «естественной» уста- новке языка в процессе формировании визуальных образов. Визуально-образный характер современности отмечается многими исследователями. Например, С. Зонтаг полагает, что общество только в том случае можно назвать современным, когда оно сосредоточено на производстве и потреблении образов. «Наша культура все больше становится визуальной. В течение последних десятилетий в западной культуре доминируют визуальные средства массовой информации над устными или текстовыми сообщениями. <...> Мы живем в культуре, которая все больше насыщается визуальными образами с разными целями и задуманными эффектами» [Sturken, Cartwright 2001, 153].

Исследователи визуального настаивают том, что визуальные медиа обладают самостоятельностью и активно воздействуют на человеческий опыт. Визуальное имеет множество средств выражения, которые изучаются с опорой на фундаментальные достижения семиотики, «культуральных исследований», психоанализа, марксизма, постструктурализма, различных видов социальной теории. Рост медиа и массовых коммуникаций ведет к теоретическому осмыслению визуальной образности в ином качестве, где внимание акцентируется на изменении функции визуальности с посреднической на конституирующую. Классические теории эстетики, история искусства подготовили фундамент для переноса визуальности в область социальных практик; таким образом, можно сказать, что сегодня невозможно не учитывать роль визуальности в формировании повседневных практик.

Появление новых форм коммуникации (онлайн коммуникации), качественно иное по- 
нимание того, что можно считать визуальными артефактами, а также изменившиеся формы повседневных практик (необходимость просмотра и выкладывания фотографий в социальные сети) можно объяснить тем, что сам акт видения подвергся тотальному пересмотру, что во многом связано с развитием цифрового общества и социальных медиа. Новые медиа-каналы коммуникации, вследствие общедоступности, характеризуются демократичностью, поскольку принимать участие в различных формах медиа-процесса теперь может любой субъект. Например, термин «культура участия», который был предложен Г. Дженкинсом, говорит о слиянии зрителя и создателя медиаконтента в одного субъекта, действующего в социокультурном пространстве. В результате акта слияния определение границы между потребителем и создателем информации затрудняется, или же граница устраняется вовсе. Данное понимание медиа размывает среду приватного, а также организовывает новую сферу телесного и личного. Вследствие деконструкции границы реального возникает новое суггестивное образование - зритель-создатель.

Разнородная методология визуальных исследований и непроясненный вопрос об объекте данной области позволяет говорить о неоднородном характере визуального. Однако, можно условно выделить два основных направления, работающих с визуальной образностью: первое направление исследований занимается анализом действия нехудожественных образов в социокультурной среде и анализирует визуальные образы как репрезентацию; второе направление берет за основу методологические наработки искусствоведческих наук и понимает образ как презентацию. Данные направления являются самыми значимыми и обширными в визуальных исследованиях и имеют качественное обоснование и предметную сферу применимости. Далее сделаем краткий обзор каждого из направлений.

Обратимся к первому направлению, которое полагает образ в качестве репрезентации. Эта концепция представлена широким кругом авторов, начиная со структуралистов и заканчивая специалистами по социологии повседневности. Особо стоит отметить
У. Эко, П. Бурдье, П. Штомпку, С. Зонтаг, М. Штуркен, Л. Картрайт, М. Джея, Д. Крэри, Д. Берджера. Данный подход обращается к образной реальности с точки зрения конструктивистской методологии и анализирует роль образов в формировании культурных смыслов, а также рассматривает активную роль медиа в социальном пространстве, в том числе проблемы, касающиеся зрения наблюдателя (пассивный / эмансипированный взгляд). Кроме того, в зону внимания попадает тема обусловленности видения скопическими режимами, которые выстраиваются под влиянием политических, экономических и культурных факторов. Скопический режим - термин, который обозначает физическое отсутствие того, на что смотрят, отсутствие видимого объекта. Данная концепция говорит о необходимости «заострить внимание на различных способах конструирования (framings) - не только объекта, но и акта его рассмотрения. Однако такое описание объекта влечет за собой не только разнообразно обоснованное социальное видение вещей. <...> Исследование также включает визуальные практики, возможные в конкретной культуре, то есть скопические (scopic) или визуальные (visual) peжимы, короче говоря, все формы визуальности» [Баль 2012, 219]. В рамках данной концепции предмет исследования визуальности расширяется, поскольку включает непосредственный повседневный опыт, содержащий в себе образную реальность нехудожественного типа. Это обращение к неэлитарной визуальности и толкование образов как подвижных образований сосредоточивает интерес не на онтологической стороне образа, а на коммуникативно-социальной. Теория образа с точки зрения репрезентации рассматривает в качестве объекта не только любые визуально доступные артефакты, но и сам акт видения, предстающий в качестве культурно сконструированного. Выше было сказано, что данная трактовка визуальной образности имеет явный уклон в сторону конструктивизма, это связано с историей происхождения визуальных исследований: на ранней стадии своего возникновения они претерпели влияние марксистской и постмарксисткой теорий. Поэтому главным объектом исследования в русле репрезенталистской теории образа являются 
практики визуальности (скопические режимы) и субъекты визуальности (наблюдатели) в пространстве социальной реальности.

Рассмотрим фигуру наблюдателя или воспринимающего объекта, а также обозначим сущность скопических режимов. Понятие зрителя связано с основными истоками визуальных исследований - историей искусств и культурными исследованиями. Визуальные образы, с которыми имеет дело наблюдатель, вышли из дисциплинарных рамок областей, долгое время имеющих монополию на всю область визуального - искусствознания и истории искусства. Визуальные исследования имеют расширенное понимание визуального, которое включает в себя медиа-исследования, визуальность архитектуры, киноэстетики, фотографии и др. Начальный этап визуальных исследований (1980-1990 гг.) был сосредоточен на социально-критическом анализе видения и визуальности, где рассматривались различные типы взгляда: «техника взгляда» как инструмент объективации, мужской взгляд, скопический режим.

Понимание наблюдателя как реципиента визуальности генеалогически связано с историей искусства и культурными исследованиями, однако, новое понимание зрителя в визуальных исследованиях расширяется за счет перехода рассмотрения визуальных артефактов от продуктов высокой культуры к широкому кругу визуальных материалов. Исследование неоднородного поля визуальных объектов и их рецепции предполагало применение особых практик смотрения. Исследователи в начальном (до конца 1990-х гг.) этапе визуальной культуры (М. Джей, Л. Картрайт, М. Штуркен, Д. Берджер, Дж. Крэри) уделяли немалое внимание понятию акта видения, самой сути зрения как основной способности субъекта воспринимать визуальные артефакты и смыслы, которые они несут. Можно сказать, что визуальные исследования развивались в качестве интерпретативной методологии: «К 80-м исследования культуры стали иметь решающее значение в гуманитаристике. В общем, можно выделить две исследовательские парадигмы: одна ориентируется на исследование культуры по образцу естественных наук, вторая опирается на герменевтику и интерпретативный метод»
[Dikovitskaya 2005, 47]. До того, как визуальные исследования обратились к понятию субъективности, ей не придавалось особого значения, однако позже она обрела свою значимость, что является показательным в отношении высокого статуса концепта наблюдателя и взгляда при аналитике визуальной образности в русле репрезенталистского направления.

Концепт наблюдателя как воспринимающего субъекта в визуальной культуре рассматривается как подлежащий эмансипаторным тенденциям. Самым ярким примером является концепт мужского взгляда Л. Малви, который описывает взгляд в качестве детерминированного социокультурными установками, имеющего власть над субъектом [Mulvey 1975]. Для визуальной культуры вопрос взгляда в значительной мере связан с вопросом власти. Однако, тенденции визуальных исследований таковы, что взгляд и акт видения становятся менее радикальными темами. Взгляд стал рассматриваться не в единственном числе, а во множественном, таким образом утвердилась позиция существования разнообразных типов взгляда, которые не делятся на мужской и женский; можно утверждать, что разные виды взгляда соотносимы с властью по-разному [Sturken, Cartwright 2001]. Как было сказано выше, тенденции смены концепции наблюдателя в визуальной культуре связаны с истоками марксизма, однако, помимо марксистской критики визуального, существуют гендерные и постколониальные критические исследования взгляда и наблюдения, этим объясняется пафос эмансипации, которым дышат исследования визуальности. Так, если смотреть с критической позиции, визуальность и визуальные образы воспринимаются в качестве артефактов, которые лишены самостоятельности, они представляются субстратами, несущими идеологическую нагрузку, которая видится исследователям в качестве нуждающейся в разоблачении. Несмотря на то, что визуальные исследования избавились от ориентации на марксисткие установки, концепция наблюдателя и зрителя все же остается под некоторым влиянием такого подхода. Визуальный образ и наблюдатель в итоге оказываются детерминированными внешними установками, от которых они 
должны быть освобождены. Фигура наблюдателя обвиняется в пассивности, и для того, чтобы перейти в качественно иное состояние активности, наблюдающему субъекту необходимо стать актором социального процесса. Визуальная культура настроена на то, чтобы освободить наблюдателя из-под власти зрелища: ее желание состоит в разоблачении, интерпретации и критике идеологии, которую содержит любая визуальность. Переосмысляется концепт зрителя: пассивный, воспринимающий субъект сменился на концепт зрителя-производителя и реципиента визуальных систем репрезентации. «Новый» видящий субъект порождает интерпретации и осмысляет условия своего бытия. Общество наблюдателей конструирует идеологическую самость через систему визуальных репрезентаций. Процесс интерпретации визуальных содержаний задан практиками смотрения, которые являются совокупностью навыков, способностей наблюдателя, его социального положения; таким образом, значение визуального образа создается в момент потребления изображения.

Согласно репрезенталистской теории, образы анализируются с точки зрения их включенности в процессы социальных взаимодействий. Визуальные исследования, рассматривающие образ в качестве репрезентации, опираются в большей мере на анализ значений и интерпретацию визуального, где значения понимаются в качестве комплексного взаимодействия образа, наблюдателя и социокультурного пространства-контекста [Sturken, Cartwright 2001]. Такой тип взаимодействия задает как доминантные в культуре значения, так и неочевидные, скрытые. Поэтому, множество значений, которые несут визуальные артефакты, толкает исследователей визуального к рассмотрению вопросов о визуальной грамотности общества наблюдателей. Так, одной из задач визуальных исследований является предоставление «зрителям, гражданам и потребителям инструменты для лучшего понимания того, как визуальные медиа помогают нам осмыслить наше общество» [Sturken, Cartwright 2001, 3]. Визуальная грамотность определяется через способность производить изображения, а также распознавать не-западный тип визуальности. Ви- зуальные исследования рассматривают концепцию визуальной грамотности с разных позиций, однако, общим основанием для них является установка на стимуляцию активности зрителя в современной социокультурной и исторической ситуации, когда визуальные образы имеют характер неоднородности, они многочисленны и многообразны. Предыдущие эпохи предполагали понимание визуальной грамотности только в аспекте распознавания произведений искусства. Однако, в современной ситуации, даже если ее не считать полностью «цивилизацией образа», обладать визуальной грамотностью становится проблематичнее, так как она включает в себя несколько видов визуальной грамотности для ориентации в основных уровнях социального пространства: в повседневности, в искусстве, в науке и даже в межличностных отношениях.

М. Штуркен и Л. Картрайт, анализируя культурные импликации активности наблюдателя и его зрительного акта, обращаются к искусству Модерна: импрессионизму, постимпрессионизму, кубизму. Нововведения, данные направлениями в искусстве были ответом перспективизму западной живописи, они демонстрировали активность и подвижный характер зрительного акта, определяя его в качестве активного, меняющегося и никогда не способного зафиксироваться, акту мысли. Смена художественных стилей в искусстве эпохи Модерна определила «видение» как бесконечно более субъективное и сложное. Новая «формула взгляда» повлекла за собой не только изменения в искусствознании, но и в повседневных практиках. Говоря об изображении в современной культуре, нельзя сказать, что оно реалистично в полной мере, что взгляд отвечает основным принципам перспективы, заданным художниками эпохи Возрождения. Современная модель визуальности предполагает пространство для свободы интерпретаций наблюдателя, однако, общекультурный уровень оказывает влияние на индивидуальное понятие вкуса: «вкус, тем не менее, это не просто дело индивидуальной интерпретации, скорее, вкус формируется исходя из опыта, связанного с чьим-либо классом, культурным бэкграундом, образованием и другими аспектами идентичности» [Sturken, Cartwright 2001, 48]. 
Социальная критика, касаемая вкуса наблюдателя, распространена в визуальных исследованиях, она ставит свои ограничения, редуцируя вкус к классовой принадлежности, говоря о социальном конструктивизме при анализе восприятия. Аналитика визуального восприятия ведется с точки зрения идеологической сконструированности, маскируя визуальное под маску некой естественности, природности, воспроизводящей, как кажется, обычный порядок вещей. Данные рассуждения не новы для культурных исследований, Р. Барт писал об этом, анализируя миф [Барт 1996] . Описание практик смотрения и их культурного измерения ограничивалось сведением к идеологии, где зритель трактовался как пассивный потребитель.

Таким образом, можно сделать вывод, что репрезенталистская парадигма визуальности претерпела эволюцию и тяготеет к конструктивисткой методологии исследования. Конструирование идет в русле действующих схем восприятия в социальных группах: на основе идеологии, архетипа, габитуса. Таким образом, субъекты, которые существуют в рамках данного процесса, являются включенными в процесс конструирования: «то, что называют «нормальным видением», является просто избирательным видением...» [Круткин 2006, 42]. Репрезенталистское направление отталкивается от понятия «скопического режима», паноптизма фукодианского толка, а также от теории социологии действия. Однако теория образа претерпевает изменения: усиливаются процессы демократизации, позволяющие расширить понятие наблюдателя. При анализе визуальности на современном этапе обнаруживается, что зрение и зритель становятся все более самостоятельными. Концепт «зритель-воспринимающий субъект» сменился на концепт зрителя-создателя визуальных систем репрезентации.

Далее, сообразно целям статьи, разберем второй подход, представляющий образ в качестве презентации. Данная проблематика была разработана рядом визуально ориентированных феноменологов, в частности М. Мерло-Понти, Ж.-Л. Нанси, Ж. ДидиЮберманом, Ж.-Л. Марийоном, Е. Петровской, Н. Сосна. Акт «смотрения», являющийся важнейшим пунктом визуальных исследова- ний, по сути является родственным феноменологической методологии, так как лежит в основе феноменологической редукции. Первым критерием действительности чего-либо, согласно феноменологии, является очевидность. Она служит основой методологии науки феноменологии, которая направлена на раскрытие и описание непосредственно усмотримых сущностей. Феноменологический подход в визуальных исследованиях акцентирует внимание на активном влиянии визуальных образов на существующую действительность: подчеркивается самостоятельность визуального образа, а также проектировочная функция образа. Взаимосвязь наблюдателя и наблюдаемого объекта, направленность субъекта на объект, интенциональные свойства визуальной образности демонстрируют один из главных тезисов феноменологического подхода: воспринимаемая вещь является существующей до тех пор, пока она находится в поле восприятия. Например, вышеобозначенное понимание образа как репрезентации определяет визуальное в качестве «зеркала» социальной жизни, где содержание образа важно настолько, насколько он является отражением социальной реальности. Феноменологический подход подчеркивает презентативную сторону образности, он прочитывает визуальные образы с точки зрения смысловой автономии, а также отмечает, что образы имеют собственные смыслы, которые не раскрыты воспринимающему их субъекту. Феноменологический подход подчеркивает презентативную сторону образности, он прочитывает визуальные образы с точки зрения смысловой автономии, а также отмечает, что они имеют собственные смыслы, которые не могут быть полностью раскрыты воспринимающему их наблюдателю. Визуальная образность, исключающая семиотическое толкование «не ограничивает спектр парадигм образности “репрезентацией” и "отображением"» [Дроздова 2015, 256]. Можно утверждать, что феноменологический подход не имеет потребности в описании контекста функционирования визуальных образов, будь то социокультурный, политический, искусствоведческий. Интерес данного подхода для современного гуманитарного знания заключается в том, что в границах структуры образа стал- 
киваются сферы зримого и незримого, что выявляет способность или неспособность образа показывать или скрывать смыслы, находящиеся в нем. Такие свойства объекта как видимость и невидимость - довольно значительная тема для онтологии образности; например Ж.-Л. Марьон в связи с этим вводит категории «смотрения» и «видения», показывая тем самым насколько сложные взаимодействия существуют в рамках рассмотрения данного понятия. «Смотреть - это извлекать из потока видимого, останавливать его, тогда как “видеть" - это воздерживаться от выбора или решения, отдаваясь на волю потока» [Марьон 2010, 87]. Проблема телесности тесно связана с сущностью визуальности. Например, М. Мерло-Понти пишет об этом так: «загадочность моего тела основана на том, что оно сразу видящее и видимое» [Мерло-Понти $1992,14]$. Проблема телесности тесно связана с сущностью визуальности, например М. Мерло-Понти пишет об этом так: «загадочность моего тела основана на том, что оно сразу видящее и видимое» [Мерло-Понти $1992,14]$. Наблюдающий субъект во время акта видения взаимодействует с миром в интересной форме: тело субъекта отдается миру, наполняется смыслами, и возвращается, наполненное новыми смыслами обратно. Связка визуальности и телесности демонстрирует следующие важные свойства визуального образа: во-первых, то, что образ есть явление, которое происходит в пространстве телесности, обусловлено чувственно-визуальным методом его восприятия. Во-вторых, образ не является сугубо внешним проявлением, например он не может быть закреплен за какимлибо одним художественным произведением, или внешним объектом, в той же мере, в какой не может быть полностью скрытым в неопределенной глубине душевной жизни субъекта. Указанный динамизм взаимодействий между субъектом и объектом, видимым и видящим, внешним и внутренним позволяет говорить о том, что образы могут демонстрироваться посредством тела, и одновременно быть вне воспринимающего субъекта, так визуальные образы в повседневных практиках обретают особую модальность бытия. Акт видения неоднороден, он включает в себя различные формы восприятия, «визуальность характеризуется внутренней синэстезией» [Дроздова 2015, 256], поэтому в качестве предмета визуальных исследований некоторые исследователи выделяют визуальное событие как то, что описывает процедуру выявления визуального образа в ходе процесса видения [Баль 2012, 220].

Феноменологическое направление делает акцент на активности как самого образа, так и субъекта восприятия. В горизонте феноменологического истолкования образности подчеркивается не репрезентативная сторона (образ как отражение социальной реальности), а презентативная. Согласно феноменологической парадигме, визуальный образ не рассматривается в качестве отражения социальной действительности, напротив, он наделен самостоятельностью и содержит в себе только ему присущие смыслы. При «вхождении» в визуальный образ человек попадает в следующую ситуацию: во время дешифровки образного смыслового содержания человек оказывается во власти образа, подтверждая тем самым особую иконическую силу визуального поля. При взаимодействии с одним и тем же визуальным объектом участники коммуникации открывают неодинаковое образное содержание, поскольку визуальные объекты поддаются в большей степени чувственному восприятию, чем например письменные и условные знаки.

Оба обозначенных выше подхода в той или иной степени утверждают активную сторону визуального образа. М. Баль примиряет эти две концепции, трактуя визуальность как поле активного взаимодействия видимых вещей, несущих в себе образы, между собой. Визуальность в таком случае воспринимается не как объект исследования, а как средство для выделения форм «жизни видимых вещей». Медийные объекты и нерукотворные (техногенной природы) изображения наделяются экзистенциальным статусом, поэтому существует интерес исследователей визуального к материальному аспекту образов и способности действовать в социальной реальности. Пространство визуальной образности, по мнению Д. Александера, имеет особое измерение: оно является своего рода лакмусовой бумагой, благодаря которой социальная действительность может быть проявлена [Alexander, 2008]. 
Это дополняет и преображает общепринятый тезис сторонников репрезенталистской теории образности, согласно которому образная реальность является лишь отражением политических и социальных отношений. Своим существованием визуальные образы создают особую иконографическую среду, внутри которой взаимодействуют автономные смыслы, меняющие опыт субъекта как таковой: «иконографический опыт разъясняет, как мы ощущаем часть нашего социального и физического окружения, как мы испытываем реальность уз, связывающих нас с людьми, которых мы знаем и которых мы не знаем, и как мы вырабатываем чувство места, гендера, сексуальности, класса, национальности, нашей профессии и даже нашей самости» [Инишев 2012, 195].

Выше мы отметили основные подходы к феномену визуального, в русле которых образ понимается: во-первых, в качестве репрезентации, во-вторых как презентация. Первое направление рассматривает визуальный образ под влиянием парадигмы конструктивизма. Предметом исследования данного направления являются визуальные способы коммуникации, которые осуществляются в оптически организованных формах в социокультурном пространстве. Также немаловажными являются понятия «наблюдатель», «скопический режим», «паноптизм», «взгляд». Второе направление по-иному выстраивает модель визуальной образности: акцент делается на автономности как главном свойстве образа, полагается, что он ведет независимое существование по отношению к воспринимающему, а также содержит собственные смыслы. При этом подчеркивается, что воспринимая визуальный образ, человек не только расшифровывает закодированное смысловое содержание, но попадает под власть образа.

В среде исследователей активно обсуждаются вопросы относительно места визуальных образов в пространстве повседневности, имеющие целью объяснить способы функционирования образов в границах человеческого тела, а также их структур и способов бытия. Выдвигается тезис о том, что визуальные объекты наделены экзистенциальным статусом, что позволяет говорить об их способности к действию в социокультурной сре- де. Выяснено, что такими объектами могут быть и нехудожественные визуальные образы, выходящие за границы эстетической теории и искусствознания. Итак, обобщив оба подхода, можно сделать вывод о том, что визуальные образы являются индексами культурных ценностей и могут качественно влиять на социокультурное пространство.

\section{СПИСОК ЛИТЕРАТУРЫ}

Баль 2012 - Баль М. Визуальный эссенциализм и объект визуальных исследований // Философско-литературный журнал «Логос». 2012. № 1 (85). C. 212-249.

Барт 1996 - Барт Р. Мифологии. М.: Изд-во им. Сабашниковых, 1996.

Дроздова 2015 - Дроздова А.В. Специфика визуальных исследований в современном гуманитарном знании // Ярославский педагогический вестник. 2015. № 3. С. 254-259.

Инишев 2012 - Инишев И. «Иконический поворот» в науках о культуре и обществе // Философсколитературный журнал «Логос». 2012. № 1 (85). C. $184-211$.

Круткин 2006 - Круткин В.Л. Пьер Бурдье: фотография как средство и индекс социальной интеграции // Вестник Удмуртского университета. Серия «Философия. Психология. Педагогика». 2000. № 3. С. 40-55.

Марьон 2010 - Марьон Ж.-Л. Перекрестья видимого. М.: Прогресс-традиция, 2010.

Мерло-Понти 1992 - Мерло-Понти М. Око и дух. М.: Искусство, 1992.

Alexander 2008 - Alexander $J$. Iconic Experience in Art and Life // Theory, Culture Society. 2008. № 25 (5). P. 1-19.

Dikovitskaya 2005 -Dikovitskaya M. Visual Culture: The Study of the Visual After Cultural Turn. Cambridge, MA: MIT Press, 2005.

Mulvey $1975-$ Mulvey $L$. Visual Pleasure and Narrative Cinema // Screen. 1975. Vol. 16 (3). P. 6-18.

Sturken, Cartwright $2001-$ Sturken M., Cartwright $L$. Practices of Looking. An Introduction to Visual Culture. Oxford: Oxford University Press, 2001.

\section{REFERENCES}

Bal M., 2012. Visual Essentialism and the Object of Visual Research. Philosophical and Literary Magazine "Logos", no. 1 (85), pp. 212-249.

Bartes R., 1996. Mythologies. Moscow, Sabashnikov Publishing House. 
C.P. Курохтина. Специфика природы образа в социокультурном пространстве

Drozdova A.V., 2015. Specificity of Visual Research in Modern Humanitarian Knowledge. Yaroslavl Pedagogical Bulletin, no. 3, pp. 254-259.

Inishev I., 2012. "Iconic turn" in the Sciences of Culture and Society. Philosophical and Literary Magazine "Logos", no. 1 (85), pp. 184-211.

Krutkin V. L., 2006. Pierre Bourdieu: Photography as a Means and Index of Social Integration. Bulletin of the Udmurt University Series "Philosophy. Psychology. Pedagogy”, no. 3, pp. 40-55.

Marion J.-L., 2010. The Crossing of the Visible. Moscow, Progress-tradition Publ.
Merlo-Ponti M., 1992. The Eye and the Spirit. Moscow, Iskusstvo Publ.

Alexander J., 2008. Iconic Experience in Art and Life. Theory, Culture Society, no. 25 (5), pp. 1-19.

Dikovitskaya M., 2005. Visual Culture: The Study of the Visual After Cultural Turn. Cambridge MA, MIT Press.

Mulvey L., 1975. Visual Pleasure and Narrative Cinema. Screen, vol. 16 (3), pp. 6-18.

Sturken M., Cartwright L., 2001. Practices of Looking. An Introduction to Visual Culture. Oxford, Oxford University Press.

\section{Information About the Author}

Sofya R. Kurokhtina, Postgraduate Student, Department of Theoretical and Social Philosophy, Saratov State University named by N.G. Chernyshevsky, Astrakhanskaya St, 83, 410012 Saratov, Russian Federation, sofic1994@mail.ru,https://orcid.org/0000-0002-8307-3648

\section{Информация об авторе}

Софья Руслановна Курохтина, аспирант кафедры теоретической и социальной философии, Саратовский государственный университет им. Н.Г. Чернышевского, ул. Астраханская, 83, 410012 г. Саратов, Российская Федерация, sofic1994@mail.ru, https://orcid.org/0000-0002-8307-3648 